\title{
OXIDATIVE STRESS AND PHYSICAL ACTIVITY
}

\author{
Marija Stanković ${ }^{1}$ and Dragan Radovanović ${ }^{1}$
}

${ }^{1}$ Faculty of Sport and Physical Education, University of Nis, Serbia

\section{SUMMARY}

The cells continuously produce free radicals and reactive oxygen species as a part of metabolic processes. Increased aerobic metabolism during exercise is a potential source of oxidative stress. Also, anaerobic physical activity and oxidative stress are interrelated because the intense anaerobic activity leads to damage proteins, lipids and nucleic acids in muscle cells and blood. Complex system of antioxidant defense, which has the enzymatic and non-enzymatic part, has a role in protecting tissues from excessive oxidative damage. Most of the research conducted so far about the impact of various forms of physical activity on levels of oxidative stress is confirmed by changes in biomarkers that indicate lipid peroxidation and proteins modification. Untrained persons, as opposed to trained, are more susceptible to major changes in the body caused by oxidative stress during physical activity. The results of researches have shown that there are no significant differences between the genders in the level of oxidative stress during physical activity and response to antioxidant supplementation possibly applied. It is interesting that, despite of numerous studies, the exact location of oxidative stress origin during physical activity has not been reliably established. In addition, research results provide insufficient evidence on the effectiveness of using antioxidant supplementation to increase the defense against oxidative stress. It is necessary further investigation about the redox status and oxidative stress during physical activity in adolescent athletes.

Key Words: physical activity, oxidative stress, antioxidants. \section{INTRODUCTION}

The cells continuously produce free radicals and reactive oxygen species (ROS) as a part of the metabolic processes. Free radicals are defined as molecules or parts of molecules that have one or more odd number of electrons in the outer cloud layer. They are characterized by a very short half-life and particularly high degree of reactivity. Harmful effects of free radicals originate from their innate tendency to get to the stage of electronic stability thus reacting with the first neighboring stable molecule taking away an electron and creating a new free radical. The affected molecule becomes unstable itself and enters into reaction with other molecules it gets near to, which results in disruption of cell components. Free radicals are created primarily during the process of oxidative phosphorylation in mitochondria (Martinović, Dopsaj, Kotur Stevuljević, \& Nešić, 2009). The highest number of free radicals emerging in vitro are or originate from reactive oxygen species (superoxide, hydroxyl, alkoxyl, peroxyl and hydroperoxyl) or reactive nitrogen species (nitric oxide, nitrogen dioxide, peroxynitrite oxidized) (Cooper, Vollaard, Choueiri, $\&$ Wilson, 2002). As a counterweight to the emerging of free radicals there is a system of antioxidant protection which can be divided into two sections: enzymatic-composed of superoxide dismutase (SOD), catalase (CAT), paraoxonase and glutathione peroxidase (GPX); and non-enzymatic - composed of the substances such as: vitamins $\mathrm{A}$ and $\mathrm{C}$, retinol, bilirubin, uric acid, reduced glutathione, thiols, coenzyme Q10, stress proteins, albumin, as well as transport proteins and proteins responsible for $\mathrm{Fe} 2+\mathrm{i} \mathrm{Cu} 2+$ deposition (transferrin - iron-carrying proteins in plasma and ferritin - a protein that is used to store intracellular iron, keeping it in soluble and nontoxic state), which bind potentially hazardous metal ions and disable their participation in production of free radicals (Martinović et al., 2009). Antioxidant enzymes 
are endogenous and their formation may be altered by certain factors. The factors of increased production of enzymatic antioxidants include physical activity and training (Finaud, Lac, \& Filaire, 2006).

Physiologists' filed of interest was earlier limited only to the matter of oxygen supply, especially for those who studied the response of organism to physical activity. However, the interest in oxygen radicals has increased as soon as the oxidative paradox was discovered, which motivated them to raise the issue whether the excessive oxygen supply during exercise can lead to oxidative stress and potential risks for biological system. (Jenkins, 2000).

The first indications that physical activity results in tissue damage caused by means of free radicals appeared in 1978, so the remaining three decades witnessed a significant increase in knowledge on that particular matter. It is well known that both active and inactive skeletal musculature produce reactive oxygen and nitrogen species though it still remains unclear the exact place of origin of oxidants during exercise (Powers \& Jackson, 2008).

Free radicals get neutralized if exposed to a complex system of antioxidant defense system (Urso \& Clarkson, 2003). Enzymatic and non-enzymatic antioxidants play an important role in tissue protection caused by excessive oxidative damage. This is particularly emphasized during exercise since physical activity is related to the production of free radicals in terms of intensity and duration of exercise as well as the physical condition of a human body. In case a low intake of antioxidants through diet and modification of antioxidant system takes place, antioxidant nutrient food supplements are established to be beneficial (Jones, 2008). However, the theoretical basis according to which antioxidants should improve athletic performance has not been clarified. In general, the research have confirmed that antioxidant supplements do not improve athletic performance but only the antioxidant status. On the other hand, higher amounts of antioxidants in regular diet may yield negative effects. Therefore, the composition, duration of intake and proper dosage of antioxidant supplements are to be conducted in a strictly controlled manner (Finaud et al., 2006).

\section{METHODS FOR OXIDATIVE STRESS ASSESSMENT}

Oxidative stress may be examined by measuring the following:

- Free radicals;
- Damage to lipids, proteins and DNA molecules caused by the effects of free radical formation;

- Activity of enzymatic antioxidants.

\section{Measurement of free radicals}

The production of reactive oxygen species can be measured by the means of spectroscopic method. Still, this method is not the most appropriate on humans due to the toxicity of materials used during this process. The examination is therefore conducted by taking blood samples, which initially get exposed to stabilizer of reactive oxygen species then centrifuged and finally the serum gets analyzed spectroscopically. Here the problem is that the application of this method cannot avoid the short half-life of the reactive oxygen species.

\section{Measurement of oxidative damage on lipids, proteins and DNA molecules}

The negative effects of free radicals can be manifested on various biomolecules (lipids, proteins and DNA molecules), and as a result of their interaction there is an increased permeability of cell membranes alongside with accelerated catabolism of proteins and gene mutation (Martinović et al., 2009).

\section{Lipid peroxidation}

The basis for measurement of oxidative stress is the measurement of the level of lipid peroxidation in the cell membrane. The lipid peroxidation decomposes lipids onto a large number of primary oxidative products such as conjugated dienes (lipid hydroperoxidase), and secondary oxidative products including malondialdehyde (MDA), F2-isoprostane or exhaled pentane, hexane or ethane. The measurement of conjugated dienes, as primary products of lipid peroxidation, is often used for this purpose.

MDA is also used in measurement of oxidative stress though it should not be the first choice in research since it is only a secondary product. This substance originates in the course of autoxidation of fatty acids. It is common to be measured through its reaction with thiobarbituric acid.

In addition to thiobarbituric acid, the concentration of thiobarbituric reactive species is often used as index of lipid peroxidation (TBARS) (Čubrilo et al., 2011).

Another way to examine oxidative damage on lipids is the analysis of pentane, hexane and ethane in the exhaled air. This is a non-invasive method but still insufficiently precise because the mentioned gasses 
may originate in other ways, not just by means of oxidation.

The most recent finding indicate that F2-isoprostanes, while undergoing peroxidation, produce arachionic acids, which are catalyzed by free radicals. Some studies show that quantification of F2-isoprostane can be a reliable method in assessment of endogenous lipid peroxidation and oxidative damage as well as other blood markers, namely oxidized LDL or antibodies for oxidized LDL.

\section{Protein modifications}

Modifications on proteins caused by free radicals induce the formation of carbonyl groups at spots in chains where amino groups are located. The increased amount of carbonyl is linked to oxidative stress. That is why the measurement of carbonyls is the method most commonly used in determining the degree of the oxidative damage on proteins. For more precise measurement of protein oxidation carbonyl/protein ratio is used. This method is more beneficial due to the long period of half-life of carbonyl. Besides, the high amount of carbonyl may reveal cumulative effects of oxidative stress, which is of crucial importance for studies dealing with longitudinal observation of the subject.

The alternative method is the quantification of oxidized amino acid (e.g. o-o-dityrosine). The advantage of this method lies in the fact that it is non-invasive (urine sample), but the interpretation of the obtained results is limited.

\section{Modifications on DNA molecules}

Reactive oxygen species cause several types of damage on DNA molecules: chain breaks, damages on protein bonds and basic modifications. Numerous methods are used to quantify these damages. The most applicable one is the method of the marker nucleotide 8-hydroxy-2-deoxyguanosine (8-OHdG), which originates in oxidation of a guanine caused by a free radical.

\section{Other indirect markers of oxidative stress}

Creatine kinase $(\mathrm{CK})$ and myoglobin are markers of cell muscle damage. These markers can also be the indirect markers of oxidative stress because the lipid peroxidation causes damage on cell membrane. However, creatine kinase and myoglobin are not the specific markers of oxidative stress especially among athletes that have a high percentage of these substance due to the athletic characteristics (e.g. physical contact), which may cause cell damage. Moreover, trained sportsmen record higher basal value of both of these substances.

\section{Measuring antioxidants}

- Enzymatic antioxidant activity (SOD, CAT, GPX) is often examined in various research. This method is valid if we need to evaluate the quality of antioxidant defense of an organism at rest, but it also can account for the importance of oxidative stress especially after the physical activity.

- Quantification of antioxidant vitamins (A, C i $\mathrm{E})$ in plasma is a common method for assessment of antioxidant defense and vitamin (A, C and E) insufficiency. Same as the antioxidant enzymes, the concentration of antioxidant vitamins is changed as a result of the oxidative stress and can therefore be used as an indirect marker of the oxidative stress.

- Other antioxidants that can be used for oxidative stress measuring include: thiol protein (GSH as the most important thiol protein in our body and GSSH as its oxidized form), uric acid (insufficiently reliable), allantoin (as an oxidized product of uric acid).

- Measuring the total antioxidant capacity (TACtotal antioxidant capacity), which gives an insight into the scope of the response of all antioxidants taken together (Finaud et al., 2006).

\section{OXIDATIVE STRESS AND PHYSICAL ACTIVITY}

The physical activity is considered to lead to an increase in the production of reactive oxygen species potentially causing cell damage. Stress proteins represent one of the general protective mechanisms which enable the cells and the organism to overcome stress. The precise relationship between physical activity, stress proteins and reactive oxygen species still remains unknown. Up-to-date information from different research are insufficient if an antioxidant food supplement is to be recommended for either athletes of physically active persons (Radovanović \& Ranković, 2004).

Intensive physical activity causes oxidative stress by all means. There is no evidence this leads to short-term effects on athletic performance though it may have long-term but not necessarily damaging effects on health. In a study conducted in 2001, it was emphasized that mitochondria in the muscle cells represent an important source of reactive substances (intermediates) such as: superoxide, hydrogen peroxide and 


\section{FIGURE 1}

Hypothetical model of reactive oxygen species effect

on muscle fatigue (modified according to Finaud et al., 2006).

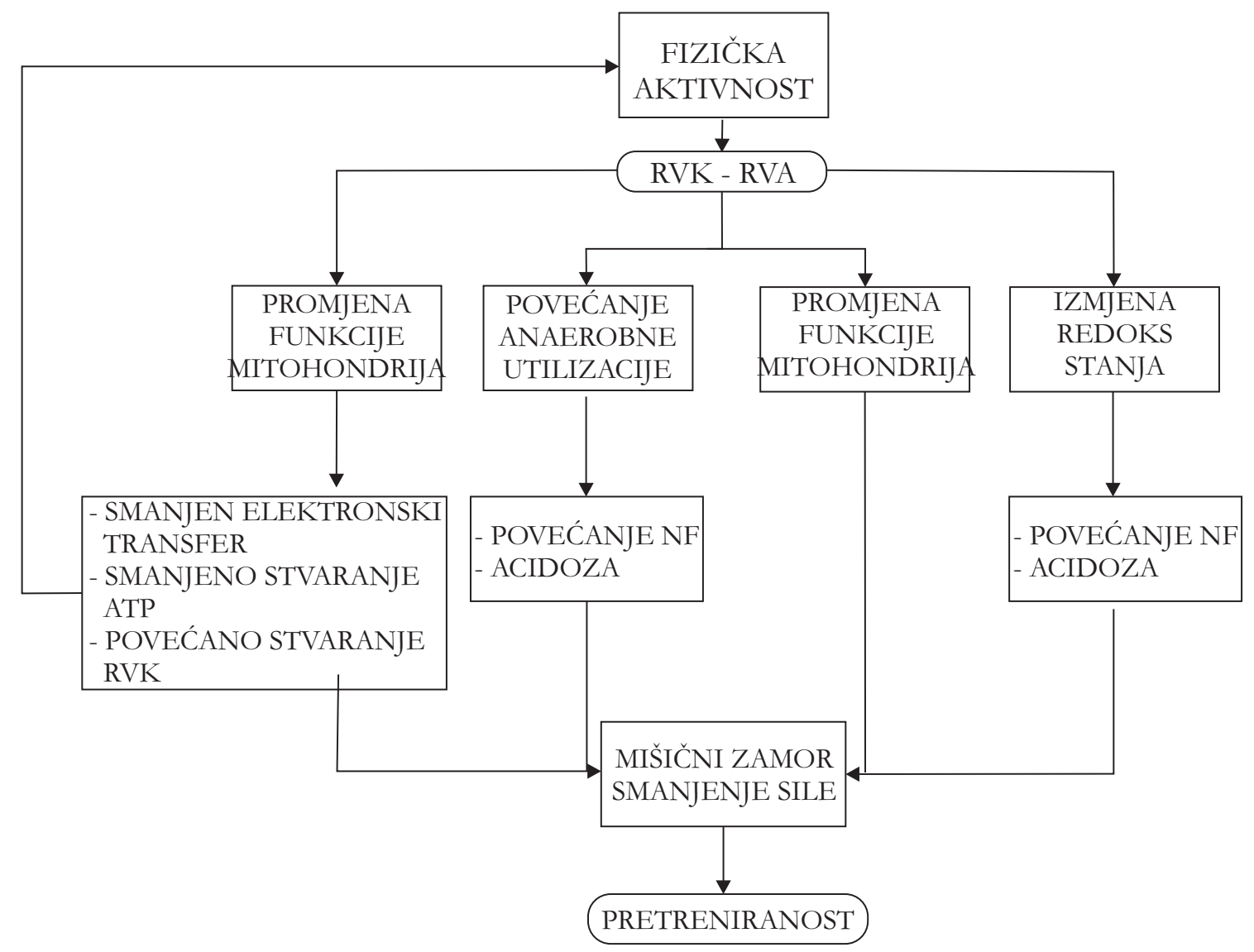

Legend: ATP - Adenosine triphosphate; IP - Inorganic phosphate; RNS - Reactive nitrogen species; ROS - Reactive oxygen species.

probably hydroxyl radical. The study proved that mitochondria can even produce nitric oxide, which is also related to the production of oxidants mitochondrial function (Leeuwenburgh \& Heinecke, 2001). A study conducted in vitro indicates that mitochondria may play a minor role in the creation of free radicals whereas Hem proteins are increasingly more important in terms of oxidative stress induction. The interaction between metmyoglobin and methemoglobin with peroxides can be a significant source of the oxidative stress during (Cooper et al., 2002).

\section{Aerobic exercise}

Davies, Quintanilha, Brooks, and Packer (1982), were first to prove that physical activity increased the production of free radicals. Many following studies dealt with the effects of exercise on the oxidative stress. They were predominantly concerned with the following sports: running, swimming and bicycling. The aerobic exercise was found to be linked to the increase in oxygen consumption $\mathrm{VO}_{2}$, which resulted in an increase in both free radical production and activity. However, it was observed that such a phenomenon was not evident at exercising of low intensity $\left(<50 \% \mathrm{VO}_{2} \mathrm{max}\right)$. In that case the antioxidant capacity was not surpassed and damages induced by free radicals did not take place. The production of free radicals and oxidative stress were higher if a more intensive physical activity was to be applied.

The increased aerobic metabolism during exercise is potentially a source of the oxidative stress. Since the health benefits of regular exercising are well-known, the possibility of the oxidative stress reduction caused by the adaptation to physical activity was looked into. That implied the increase of antioxidant defense, decrease of basal production of antioxidant production, and reduced loss of radicals during oxidative phosphorylation (Leeuwenburgh \& Heinecke, 2001).

The increased production of reactive oxygen and nitrogen species as well as oxidative stress occur among top athletes when exposed to the maximum load 
regardless of the type of energetic demand of a particular sport (aerobic, aerobic-anaerobic, anaerobic). The effects of longtime training of various sports (bicycling, rowing and taekwondo) onto the parameters of the oxidative stress at rest have been examined. The progressive loading test in its interval from the fourth to tenth minute of resting has been applied for this purpose. The results of the study have showed that training practice of various sports affects the establishment of different basal level of nitrite and concentration of thiobarbituric reactive species (TBARS) in such a manner that taekwondo records the lowest level of nitrite, followed by bicycling and rowing with the highest level of nitrite, whereas in terms of TBARS level rowing has the lowest level followed by taekwondo and bicycling. However, in terms of the level of parameters of the oxidative stress, no significant difference has been determined regardless of the type of sport and irrespective of the ten minute long resting period (Čubrilo et al., 2011).

Although the benefits of anaerobic physical activity cannot be disputed, there is plenty of evidence that a high intensity anaerobic physical activity leads to oxidative stress. The prolonged and intensive anaerobic exercise drastically affects the increase of reactive oxygen species production, which results in antioxidant insufficiency and leads to the oxidative stress, cell mutations, tissue and immune system damage.

The anaerobic physical activity and oxidative stress are closely linked in the sense that the intensive anaerobic physical activity results in damage of proteins, lipids and nucleic acids in muscle cells and blood. There is evidence that regular anaerobic physical activity increases the oxidative stress. Large number of research abounds in details on aerobic physical activity but still lack to fully clarify the issue of oxidative stress and anaerobic physical activity. According to current knowledge, the oxidative modifications are similar to those caused by the oxidative stress during aerobic physical activity, but that is still to be thoroughly researched.

\section{OXIDATIVE STRESS DURING PHYSICAL EXERCISE IN HEALTHY PERSONS}

The reactive oxygen species play an important role as mediators of damage and inflammation of skeletal muscle after strenuous physical activities. Large amount of these compounds is formed from the increased oxygen consumption in mitochondria and increased electron transport flux (Sacheck \& Blumberg, 2001). The reactive oxygen species (ROS) have a double effect on the contractile ability of rested skeletal muscles. The low level of reactive oxygen species in basic conditions is necessary for normal production of muscle force. The selective consumption of ROS in an unfatigued muscle by means of superoxide dismutase or catalase causes decline of force. As opposed to that, the mean values of ROS induce the increase of force. This positive effect has been confirmed at higher concentrations of ROS; the production of force recedes depending on the time and quantity. During strenuous physical activity these compounds contribute to the occurrence of acute muscle fatigue. ROS occur in muscles faster than they can be amortized by endogenous antioxidants. As ROS get accumulated in a muscle that performs labor, the production of force gets inhibited in it. Other factors that can increase activity of ROS include aging, muscle injuries and some diseases (Radovanović \& Ranković, 2004).

\section{Oxidative stress during physical activity in untrained persons}

Many studies have examined the difference among genders in terms of the oxidative stress during exercise and the influence of antioxidant supplements (vitamins $\mathrm{E}$ and $\mathrm{C}$ ). The results show that women at rest have higher level of antioxidants when compared to men. The markers of oxidative stress (protein carbonyl, oxidized and reduced glutathione, malondialdehyde, vitamins $\mathrm{C}$ and $\mathrm{E}$ in plasma) as the response on physical activity of similar scale and intensity almost grow equally at both genders (Goldfarb, McKenzie, \& Bloomer, 2007).

The study that examined the influence of physical activity and food supplementation with carnitine onto the oxidative stress arising as the response on aerobic and anaerobic power test recorded the following results: MDA was under a minimal influence of physical activity but had lower values at rest among groups of respondents who undergone carnitine diet supplementation, whereas the values of hydrogen peroxide and xanthine oxidase higher after the physical activities in all groups. The physical activity accompanied by carnitine supplementation may have influence on the MDA level decrease at rest. However, the influence on biomarkers of the oxidative stress is relatively small (Bloomer \& Smith, 2009).

The use of dietary antioxidants, such as vitamin $\mathrm{E}$, in order to reduce the oxidative damage on muscles, has mixed success. The difference in the obtained results is due to the testing of different antioxidants, the nature and extent of physical activity, age and physical condition of the respondents, as well as the applied methodology for the study of oxidative stress (Sacheck \& Blumberg, 2001). 
A high-calorie diet causes the oxidative stress while acute physical activity can potentially reduce stress. The influence of physical activity on triglycerides and glucose in obese Caucasian women was the subject of the following study. Lipemia and oxidative stress after meals are lower in obese black women when compare to obese white women, while the acute physical activity before a high-calorie diet did not generate any changes in the state of organism after meals in both groups (Bloomer, Cole, \& Fisher Wellman, 2009).

The gender and the status of physical fitness may influence the oxidative stress after meals. All the analyzed biomarkers of oxidative stress (malondialdehyde, hydrogen peroxide, activity of xanthine oxidase, protein carbonyl and triglycerides) showed lower values in trained persons except for the TEAC (trolox equivalent antioxidant capacity), which further indicates that gender, and not the status of physical fitness, influence on the oxidative stress after meals. Women are also recorded to have a significantly lower level of oxidative stress biomarkers after meals when compared to men (Bloomer, Ferebee, Fisher Wellman, Quindry, \& Schilling, 2009).

Older organisms are more susceptible to the oxidative stress during exercise due to the biochemical changes taking place with aging thus contributing to the formation of reactive oxygen species. The old age is also known to be prone to increased muscle injuries, and the inflammatory response of "the old" muscle may lead to the extended oxidative stress (Ji, 2001).

\section{Oxidative stress during physical activity in trained persons}

The production of ROS is linked to the muscle activity and depends on genes. In this regard, there is considerable interest in the possibility of these mediators to be part of muscle adaptation on the physical activity. Muscles adapt to physical activity by increasing gene expression in the regulation of antioxidant enzymes including superoxide dismutase, catalase and glutathione peroxidase (Radovanović \& Ranković, 2004).

The parameters of oxidative stress are gender-determined in athletes, which accounted for the examination or relation between iron transport proteins (serum ferritin and transferrin, soluble transferrin receptor) and $\mathrm{C}$-reactive proteins as proteins of acute-phased reaction with oxidative stress. Some 73 sportswomen and 65 sportsmen took part in the following study. The results showed that transferrin and ferritin as well as the proteins of acute-phased reaction were negatively related to the oxidative stress. The authors concluded that the variations in the level of ferritin may have contributed to a different level of the oxidative stress among sportsmen and sportswomen. The largest share in the variability of all parameters of the oxidative stress $(46.3 \%)$ was attributed to the gender difference. The sportswomen were thus showed to be more susceptible to the oxidative stress (Dopsaj, Martinović, Dopsaj, Stevuljević, \& Bogavac Stanojević, 2011).

An athlete's diet is often accompanied with antioxidant supplements in order to offset the oxidative stress occurring at physical strain. Research results still provide insufficient evidence on the reduction of the oxidative stress if such dietary supplementation is to be applied, though an increase in the oxidative capacity has been established (Urso \& Clarkson, 2003).

The antioxidant supplementation (vitamins $\mathrm{C}$ and $\mathrm{E}$, and selenium) combined with an eccentric exercise with additional burden (of the flexor in the elbow joint) in young trained showed that: applied program of physical activity influenced the reduce the amount of biomarkers in oxidative stress (protein carbonyl in plasma, malondialdehyde, oxidized and reduced glutathione); the antioxidant supplements affected the reduced increase of malondialdehyde and protein carbonyls (Goldfarb, Bloomer, \& McKenzie, 2005).

The effect of two different forms of antioxidant supplementation (vitamins $\mathrm{E}$ and $\mathrm{C}$ in one case and fruit and vegetable juice concentrate in the other) on the oxidative stress during aerobic exercise in trained men and women was the subject in Bloomer, Falvo, Fry, Schilling and Smith's (2009) study. The results of the study indicated that both types of supplementation, administered in the course of two weeks, affect the reduced increase of protein carbonyls after the aerobic physical activity lasting for 30 minutes, whereas they had no effect on changes in MDA and 8-OhdG (Bloomer, Goldfarb, \& McKenzie, 2006).

The influence of antioxidant supplementation in top female volleyball players in the course of six-week training period in preseason was the subject of the following study. The twenty-eight respondents were divided into two groups: experimental $(n=16)$, in which the volleyball players took the antioxidant cocktail (vitamin E, vitamin $\mathrm{C}$, zinc gluconate and selenium), and control group $(n=12)$ in which supplementation was not administered. The blood samples were taken before and after the six-week training period. The following were put on the analysis: levels of reactive oxygen metabolites (ROM) as dependent variables and malondialdehyde; superoxide anion radical, "advanced" products of protein oxidation and lipid hydroperoxide as independent variables. 
The correlation between the levels of reactive oxygen metabolites and other parameters of the oxidative stress was reduced in the experimental group and it was also observed that the application of antioxidant supplementation in the preseason prevents antioxidant defense depletion (Martinović et al., 2011), which was found to be important bearing in mind that female athletes were established to be more susceptible to the oxidative stress (Dopsaj et al., 2011).

Radovanovića et al. (2008) examined the change in certain biomarkers of the oxidative stress during Tae Bo ( 7 female respondents, 12 weeks of training sessions) and Pilates training sessions (7 female respondents, 12 weeks of training sessions). The blood samples were taken at rest both at the beginning and in the end of the appropriate training period, and they were analyzed in order to establish the markers of the oxidative stress (malondialdehyde, catalase in plasma, carbonyl and sulfhydryl groups, total antioxidant status). Statistically significant increase of the total antioxidant status after Tae Bo training session as well as the activity of catalase in plasma after Pilates training program were the most important findings of this research. Due to different metabolic demands during these two types of training sessions, the conclusion was that the increased oxygen consumption was not sole mechanism causing the oxidative stress during exercise.

The health consequences of increased oxidative stress during training or performing a highly strenuous sport have not been totally elucidated though it is a well-known fact that such a physical activity is related to the improvement of endogenous antioxidant defense. A research conducted on well-trained men practicing and competing in triathlon showed that the level of all analyzed biomarkers of oxidative stress returned to the initial level (the level before competition) five days after the race, and that there was a correlation between the state of being well-trained, markers of the oxidative stress and the activity of antioxidant enzymes. To conclude, the alternatives of the antioxidant defense system in this population prevent the occurrence of long-term oxidative stress during intensive physical strain (Neubauer, König, Kern, Nics, \& Wagner, 2008).

The research examining changes in parameters of anaerobic and aerobic capacities alongside with the biomarkers of oxidative stress among eight selected judoists during 12 -week long training program in preseason showed that the increase in parameters of anaerobic capacity was accompanied by the increase balance disorder between reactive oxygen species and the overall antioxidant system in the organism, statistically significant increase in the values of malondi- aldehyde in erythrocytes and catalase in plasma (Radovanović, Bratić, Nurkić, Kafentarakis, \& Kolias, 2008).

The study of Radovanović, Bratić, and Nurkić (2008) dealt with the oxidative stress markers in young judoist during four weeks preparation period training program which included: strength training, training techniques and judo fights (randors). Ten young judoists were part of this study. The blood samples were taken at rest before and after four weeks preparation period training program, and the analysis included changes in oxidative stress markers (MDA, CAT, carbonyl and sulfhydryl groups and total antioxidant status). The obtained results indicated that such a training program did not bear any statistically significant effects on the parameters of oxidative stress in well-trained young judoists, so the conclusion was that oxidative defense in the organism was sufficient in dealing with the oxidative stress.

During twelve weeks comparative strength-endurance training program, the authors monitored the change of oxidative stress parameters in 14 judoists divided into the experimental and control group. Besides, the effects of such a training program were compared to the normal training program effects in terms of maximal oxygen consumption, parameters of anaerobic capacity, situational-motor abilities and body composition. The obtained results showed that the comparative strength-endurance training led to an increase in maximal oxygen consumption and anaerobic capacity, but also caused the balance disorder between reactive oxygen species and antioxidant system of the entire body. This study also considered the possibility that pro-oxidants represented a stimulus for the increase of antioxidant defense aiming to achieve maximum adaptation on such a type of training (Radovanović et al., 2009).

The length of sports experience also has an effect on occurrence, level and possibility of adaptation on the oxidative stress. The study of Martinovic et al. measured the parameters of oxidative stress in 54 top female volleyball players, which were divided in three groups depending on the length of their sports experience: 1 st group - under 8 years of experience, 2 nd group - from 8 to 10.5 years of experience, 3rd group - over 10.5 years of experience; all in order to examine the influence of years long training on the oxidative stress. As the most reliable indicators the following were singled out: activity of superoxide dismutase (SOD) - statistically significant higher values in group 3 as opposed to group, and the level of superoxide anion - statistically significant lower values in group 3 as opposed to group 1. The status of parameters of oxidative stress pointed to a high 
percentage $(68.5 \%)$ in terms of the existence of differences in occurrence and adaptation onto the oxidative stress in top female volleyball players with different length of sports experience (Martinović et al., 2009).

There are still few available data concerning the system of antioxidant defense and its response to exercise in adolescents and young athletes. The effect of years long training of handball on the redox status of adolescent players (from 16 to 19 years of age) as well as the correlation between the homeostasis redox and aerobic power was examined in the study of Đorđević et al. (2011). The collected blood samples included 33 young handball players and 14 non-athletes of the same age who underwent the test of maximum progressive load in order to establish their $\mathrm{VO}_{2}$ max. The handball players showed a much higher activity of superoxide dismutase and much lower activity of catalase; the most evident results were present in those who had low or average aerobic power. The aerobic power and years long regular exercise proved themselves to have important influence in redox status improvement in the youth and adolescents, which provides for the better adaptation on the oxidative stress (Ibid).

The application of similar anaerobic physical activities (squats and sprints) at anaerobically trained persons resulted in minor differences in the level of oxidative stress and muscle tissue injuries. Physiological responses in that case were probably reduced due to the adaptation of organism on regular and strenuous anaerobic (Bloomer, Falvo, Fry, Schilling, \& Smith, 2006a).

The study of Đorđević et al. (2010) examined the interaction between nitrogen oxide and anion radicals during the increasing load in 19 top-class footballers. The analysis of blood samples collected during the last 10 seconds of each phase of the maximal progressive load test indicated that the regression lines of nitrites and superoxide anion radicals surpass the level of anaerobic threshold, which may have hinted that the very anaerobic threshold could have been of the utmost importance in both anaerobic and aerobic metabolism. The long-time physical activity proved to have an increasing effect in terms of bioavailability of nitrogen oxide and have positive correlation compare to the maximal oxygen consumption.

\section{OXIDATIVE STRESS DURING PHYSICAL ACTIVITY IN PERSONS WITH IMPAIRED HEALTH STATUS}

Oxidative stress and disbalance between the production of reactive oxygen species and capacity of antioxidant defense of an organism is closely linked with the age and different illnesses such as: cardiovascular and respiratory diseases and diabetes.

Persons with disturbed metabolism of lipids and glucose have an increased risk of oxidative stress after meal. The effects of acute physical activity on the level of triglycerides and biomarkers of the oxidative stress have been examined in prediabetic women, who exercised 15 minutes after meal. The results showed that this type of physical activity did not have any influence on the level of triglycerides and the occurrence of oxidative stress, so it could be assumed that a more intensive exercising was to be called for if measurable effects were to be come at (Melton, Tucker, Fisher Wellman, Schilling, \& Bloomer, 2009).

Atalay and Laaksonen (2002) collected many data on the interdependent mechanisms, which increase the production of reactive oxygen and nitrogen species and reduce the antioxidant defense in diabetics. The modern medicine considers the regular exercising to be of great importance in treatment of diabetes. Although acute exhausting exercise increases the oxidative stress, the study showed that regular physical activity regulates the antioxidant defense. Should regular exercise prove to have any protective effects against the oxidative stress in diabetics, which would have a direct impact on the use of physical activity as a safe therapeutic modality in the treatment of diabetes.

Programmed physical activity is one of the key elements in accomplishment of sound glycemic control and attenuation of possible cardiovascular diseases resulting from diabetes type 2 . The leading clinical findings emphasize the therapeutic benefit of exercising, so patients with such diseases should be stimulated to participate in specially designed intervention programs (Praet \& van Loon, 2009).

\section{CONCLUSION}

The discovery of the so-called oxidative paradox inspired the researches to intensify their efforts in the realm of oxidative stress, antioxidant defense and the influence of physical activity on these phenomena. Nearly all studies from the last decade dealing with the oxidative stress and physical activity analyzed MDA, 8-ONdG and protein carbonyls as biomarkers of change occurring in an organism. Most of the studies confirmed the changes in biomarkers indicating lipid peroxidation and modifications on proteins. Untrained persons, as opposed to the trained ones, are more susceptible to major changes in the body 
caused by oxidative stress during physical activity. The results of researches have showed that there are no significant differences between the genders in the level of oxidative stress during physical activity and the response of the body on the application of antioxidant supplementation; however, the latest findings reveal that female athletes are more susceptible to oxidative stress than male athletes. The proteins responsible for transport and deposition of iron (transferrin and ferritin) should be punt under a more detailed examination in the context of monitoring the occurrence and adaptation onto the oxidative stress. Practicing and training of different types of sports affects the establishment of different basal levels of nitrite and concentration of thiobarbituric reactive species (TBARS). The regression lines of nitrite and superoxide anion radicals surpass the anaerobic threshold at maximal progressive load testing, which indicates that the anaerobic threshold could be of great importance when discussing both anaerobic and aerobic metabolism.

The increased oxidative stress typically occurs after meal so the physical activity, taking place before or after meal, does barely nothing to affect that phenomenon, especially among people with impaired health status. It is noteworthy that despite numerous relevant studies, the exact place of oxidative stress occurrence remains unidentified, as well as the exact benefit of antioxidant supplementation as a response to oxidative stress. With an ever increasing number of the youth being exposed to strenuous trainings, it becomes necessary to devote attention to research dealing with antioxidant defense, redox status and antioxidant stress among this population.

\section{ACKNOWLEDGEMENTS}

This work was supported by grant number 41018 III from the Ministry of Science and Technological Development of the Republic of Serbia.

\section{REFERENCES}

Atalay, M., \& Laaksonen, D.E. (2002). Diabetes, oxidative stress and physical exercise. Journal of Sports Science and Medicine, 1, 1-14.

Bloomer, R. J., Cole, B., \& Fisher-Wellman, K. H. (2009). Racial differences in postprandial oxidative stress with and without acute exercise. International Journal of Sport Nutrition and Exercise Metabolism, 19(5), 457-472.

Bloomer, R. J., Falvo, M. J., Fry, A. C., Schilling, B. K., \& Smith, W. A. (2006). Oxidative stress response in trained men following repeated squats or sprints. Medicine and Science in Sports and Exercise, 38(8), 1436-1442. doi: 10.1249/01. mss.0000227408.91474.77

Bloomer, R. J., Ferebee, D. E., Fisher-Wellman, K. H., Quindry, J. C., \& Schilling, B. K. (2009). Postprandial oxidative stress: influence of sex and exercise training status. Medicine and Science in Sports and Exercise, 41(12), pp. 2111-2119. doi: 10.1249/MSS.0b013e3181a9e832

Bloomer, R. J., Goldfarb, A. H., \& McKenzie, M. J. (2006). Oxidative stress response to aerobic exercise: comparison of antioxidant supplements. Medicine and Science in Sports and Exercise, 38(6), 1098-1105. doi: 10.1249/01. mss.0000222839.51144.3e

Bloomer, R. J., \& Smith,W, A. (2009). Oxidative stress in response to aerobic and anaerobic power testing: Influence of exercise training andcarnitive supplementation. Res Sports Med, 17(1), 1-16. doi: 10.1080/15438620802678289; PMid: 19266389

Cooper, C. E., Vollaard, N. B. J., Choueiri, T., \& Wilson, M. T. (2002). Exercise, free radicals and oxidative stress. Biochemical Society Transactions, 30, 280-285. doi: 10.1042/BST0300280

Čubrilo, D., Đordjević, D., Živković, V., Đurić, D., Blagojević, D., Spasić, M., \& Jakovljević, V. (2011). Oxidative stress and nitrite dynamics under maximal load in elite athletes: relation on sport type. Molecular and Cellular Biochemistry, 355(1-2), 273-279. doi: 10.1007/s11010-0110864-8; PMid: 21562799

Davies, K. J., Quintanilha, A. T., Brooks, G. A., \& Packer, L. (1982). Free radicals and tissue damage produced by exercise. Biomechanical and Biophysical Research Communications, 107, 1198-1205. doi: 10.1016/S0006-291X(82) 80124-1

Đordjević, D., Jakovljević, V., Čubrilo, D., Zlatković, M., Živković, V., \& Đurić, D. (2010). Coordination between Nitric Oxide and Superoxide Anion Radical During Progressive Exercise in Elite Soccer Players. The Open Biochemistry Journal, 4, 100-106. oi: 10.2174/ 1874091X01004010100; PMid: 21633721; PMCid: 3104555

Đordjević, D., Čubrilo, D., Macura, M., Barudžić, N., Đurić, D. \& Jakovljević, V. (2011). The influence of training status on oxidative stress in young male handball players. Molecular and Cellular Biochemistry, 351(1-2), 251-259. doi: 10.1007/s11010-011-0732-6; PMid: 212 64496 
Dopsaj, V., Martinović, J., Dopsaj, M., Stevuljević, J. K., \& Bogavac-Stanojević, N. (2011). Genderspecific oxidative stress parameters. International Journal of Sports Medicine, 32(1), 14-19. doi: 10.1055/s-0030-1267930; PMid: 21086243

Finaud, J., Lac, G., \& Filaire, E. (2006). Oxidative Stress: Relationship with Exercise and Training. Sports Med, 36(4), 327-358. doi: 10.2165/000072 56-200636040-00004; PMid: 16573358

Goldfarb, A. H., Bloomer, R. J., \& McKenzie, M. J. (2005). Combined antioxidant treatment effects on blood oxidative stress after eccentric exercise. Medicine and Science in Sports and Exercise, 37(2), 234-239. doi: 10.1249/01. MSS.0000152887.87785.BE

Goldfarb, A. H., McKenzie, M. J., \& Bloomer, R. J. (2007). Gender comparisons of exerciseinduced oxidative stress: influence of antioxidant supplementation. Applied Physiology, Nutrition and Metabolism, 32(6), 1124-1131. doi: 10.1139/H07-078; PMid: 18059586

Jenkis, R. R. (2000). Exercise and oxidative stress methodology. The American Journal of Clinical Nutrition, 72, 670-674.

Ji, L. L. (2001). Exercise at old age: does it increase or alleviate oxidative stress? Annals of the New York Academy of Science, 928, 236-247. doi: 10.1111/j.1749-6632.2001.tb05653.x

Jones, D. P. (2008). Radical-free biology of oxidative stress. American Journal of Physiology, Cell Physiology, 295(4), 849-868. doi: 10.1152/ ajpcell.00283.2008; PMid: 18684987;

PMCid: 2575825

Leeuwenburgh, C., \& Heinecke, J. W. (2001). Oxidative Stress and Antioxidants in Exercise. Current Medicinal Chemistry, 8, 829-838. PMid: 11375753

Martinović, J., Dopsaj, V., Kotur Stevuljević, J., \& Nešić, G. (2009). Fiziološki značaj oksidativnog stresa kod vrhunskih odbojkašica [The physiological significance of oxidative stress in elite volleyball players]. In V. Koprivica and I. Juhas (Eds.), International scientific conference »Theoretical, Methodological and Methodical Aspects of Competitions and Athletes' Preparation« (pp. 365-369). Belgrade, Serbia: Fakultet sporta i fizičkog vaspitanja, Ministarstvo omladine i sporta Republike Srbije.

Martinović, J., Dopsaj, V., Dopsaj, M. J., KoturStevuljević, J., Stefanović, A., \& Nešić, G. (2009). Long-term effects of oxidative stress in volleyball players. International Journal of Sports Medicine, 30(12), 851-856. doi: 10.1055/s-0029 -1238289; PMid: 20013555
Martinović, J., Dopsaj, V., Kotur Stevuljević, J., Dopsaj, M., Vujović, A., Stefanović, A., \& Nešić, G. (2011). Oxidative stress biomarker monitoring in elite women volleyball athletes during 6-week training period. The Journal of Strength \& Conditioning Research, 25(5), 1360-1367. doi: 10.1519/JSC.0b013e3181 d85a7f; PMid: 21157395

Melton, C. E., Tucker, P. S., Fisher Wellman, K. H., Schilling, B. K., \& Bloomer, R. J. (2009). Acute exercise does not attenuate postprandial oxidative stress in prediabetic women. The Physician and sportsmedicine, 37(1), 27-36. doi: 10.3810/PSM.2009.04.1680;

PMid: 20048485

Neubauer, O., König, D., Kern, N., Nics, L., \& Wagner, K. H. (2008). No indications of persistent oxidative stress in response to an ironman triathlon. Medicine and Science in Sports and Exercise, 40(12), 2119-2128. doi: 10.1249/ MSS.0b013e3181824dab

Powers, S. K., \& Jackson, M. J. (2008). ExerciseInduced Oxidative Stress: Cellular Mechanisms and Impact on Muscle Force Production. Physiological Reviews, 88, 1243-1276. doi: 10.1152/physrev.00031.2007; PMid: 18923182; PMCid: 2909187

Praet, S. F., \& van Loon, L. J. (2009). Exercise therapy in type 2 diabetes. Acta Diabetologica, 46(4), 263-278. doi: 10.1007/s00592-009-01290; PMid: 19479186; PMCid: 2773368

Radovanović, D., Bratić, M., \& Nurkić, M. (2008). Oxidative stress response in young judoists during four weeks preparation period training program. In J. Cabri, F. Alves, D. Araújo, J. Barreiros, J. Diniz, and A. Veloso (Eds.), Book of Abstracts of the 13th Annual Congress of the European College of Sport Science (p. 310). Estoril, Portugal: Editorial do Ministério da Educação.

Radovanović, D., Bratić, M., Nurkić, M., Cvetković, T., Ignjatović, A., \& Aleksandrović, M. (2009). Oxidative stress biomarker response to concurrent strength and endurance training. General Physiology and Biophysics, 28(1), 205-211.

Radovanović, D., Bratić, M., Nurkić, M., Kafentarakis, I., \& Kolias, C. (2008). Effects of specially designed training on functional abilities and blood markers of oxidative stress in elite judo athletes. In A. Hökelmann and M. Brummund (Eds.), Book of Proceedings of the World Congress of Performance Analysis of Sport VIII (pp. 393-397). Magdenburg, Germany: Otto-von-Guericke-Universität. 
Radovanović, D., Jakovljević, V., Cvetković, T., Ignjatović, A., Veselinović, N., \& Dondur, S. (2008). Effects of different exercise program on blood markers of oxidative stress in young women. Fiziologia, 18(3), 16-20.

Radovanović, D., \& Ranković, G. (2004). Oxidative stress, stress proteins and antioxidants in exercise. Acta Medica Medianae, 43(4), 45-47.
Sacheck, J. M., \& Blumberg, J. B. (2001). Role of vitamin $\mathrm{E}$ and oxidative stress in exercise. Nutrition, 17(10), 809-814. doi: 10.1016/S08999007(01)00639-6

Urso, M. L., \& Clarkson PM. (2003). Oxidative stress, exercise, and antioxidant supplementation. Toxicology, 189(1-2), 41-54. doi: 10.1016/S0300-483X(03)00151-3

Received: April 3, 2012

Revision received: May 21, 2012

Accepted: June 3, 2012

Correspodence to: Dragan Radovanović, MD, PhD Faculty of Sport and Physical Education

Čarnojevića 10a 18000 Niš

Serbia

E-mail: drananiste@yahoo.com

Phone: 00381631045935 